\title{
New Ideas on the Design of the Web-Based Learning System Oriented to Problem Solving From the Perspective of Question Chain and Learning Community
}



Yin Zhang ${ }^{1,2}$ and Samuel K. W. Chu' 2

${ }^{1}$ Department of Education, Ocean University of China, Qingdao, P. R. China

${ }^{2}$ Faculty of Education, The University of Hong Kong, Hong Kong SAR, P. R. China

\begin{abstract}
In recent years, a number of models concerning problem solving systems have been put forward. However, many of them stress on technology and neglect the research of problem solving itself, especially the learning mechanism related to problem solving. In this paper, we analyze the learning mechanism of problem solving, and propose that when designing Web-based problem solving systems, more attention should be paid to the learning mechanism involved in the problem solving process than to the technology itself. On the basis of that, some new ideas on the design of the problem solving systems are put forward in order to promote the rapid development of the Web-based problem solving systems.
\end{abstract}

Keywords: web-based problem solving systems; learning mechanism; question chain; learning community

\section{Introduction}

What is problem solving? Problem solving refers to the process of solving problems in which one needs to transform the given state into the desired goal state by looking for available methods (Lovett, 2002; Jonassen, 2007). Even though problem solving originates from cognitive and experimental psychology, it has received intensive attention by educational researchers throughout the world. Different from the psychological definition of problem solving mentioned above, in educational context, problem solving refers to learning to solve real-life problems with knowledge and skills learned, which may not guarantee that best-fit solution could be reached (van Merriënboer, 2013). 
According to Popper (1999: 99-104), "All life is problem solving". If this is correct, it requires educators to take problem solving as a critical educational goal, and focus on fostering students' problem solving abilities. In the last decades, many have researched into the instruction of problem solving, and explored various ways to promote students' learning for problem solving.

With the rapid development of network technology, a large number of Web-based learning systems oriented to problem solving have emerged, which can effectively promote students' learning outcomes and their satisfaction towards learning. Spiro, Coulson, Feltovich, and Anderson (1988), and Spiro, Morsink, and Forsyth (2012) first put forward cognitive flexibility theory which provided theoretical foundation for the introduction of network into problem solving. From then on, more and more Web-based learning systems oriented to problem solving emerged. The Cognitive and Technology Group at Vanderbilt (CTGV) developed the Jasper Woodbury problem solving series for middle school mathematics learning ("The Adventures of Jasper Woodbury," n.d.). Another typical example is IMMEX (Interactive Multi-Media Exercises) software at UCLA which developed technologies around the broad model of problem solving to probe the development of student understanding in multiple domains (Underdahl, Palacio-Cayetano, \& Stevens, 2001). In addition, some Web-based learning systems for problem solving in specific fields were developed. For example, Lin (2011) designed a Web-based collaborative-learning system for statistical problem solving. Chang, Wu, Weng, and Sung (2012) designed a game-based problem-posing system for mathematics learning. Development modes also became more flexible. Some researchers designed systems by themselves, and others made use of open source platforms, such as Moodle, to develop Web-based learning systems for problem solving (Lin, 2011).

These Web-based learning systems oriented to problem solving have some limitations as follows:

- The classification of problems in psychology is not applicable to the practice of problem solving in the field of education. The theory of 'problem solving' was first put forward by psychologists, in which problems were divided into two categories, i.e., well-structured problem and ill-structured problem. Researchers have designed and developed different systems to support ill-structured or well-structured problem solving. For example, Chen and Ge (2006) proposed the design of a web-based cognitive modeling system to support ill-structured problem solving. Wu, Wang, Spector, and Yang (2013) designed a dual-mapping system for ill-structured problem solving. However, the classification of problems in psychology is not applicable to the practice of problem solving in the field of education. Firstly, problems in the real world are usually in the middle of the continuum between well-structured and ill-structured problems (Jonassen, 1997, 2012), therefore the web-based systems to single category of problem solving will affect students' knowledge and understanding of real problems. Secondly, since domain-specific knowledge which helps solve problems is different among students, an ill-structured problem for some students may be a well-structured one for others. Thus the classification of problems is not fixed for students. Thirdly, this classification of problems and corresponding research ignore students who are the users of web-based systems. 
- Although these systems have introduced question asking as an important cognitive strategy to improve students' problem solving performance, they lack the systematic design of question asking. As an important cognitive strategy for providing scaffolding for student problem solving, question asking is attracting more and more attention from researchers (Cheung \& Hew, 2004; Ge \& Land, 2003; Li et al., 2014). Browne and Keeley (2007) thought that question asking could promote critical thinking, which was essential for problem solving (Jonassen, 2008). Although researchers have carried out studies on different forms of question asking, few studies have been carried out on question asking itself, especially the systematic design of question asking. In the existing problem solving systems, questions are usually arbitrary and separate. Thus it is difficult to guide students effectively to find solutions to problems.

- Little research has been carried out on the analysis and design of internal organization structure in existing problem solving systems. Peer collaboration is another promising strategy for providing scaffolding for student problem solving (Johnson, 1988; Mergendoller, Bellisimo, \& Maxwell, 2000; Adler, Zion, \& Mevarech, 2015). Many existing problem-solving systems provided learning environments and communication tools to facilitate collaboration between students. For example, Scardamalia, Bereiter, and Lamon (1994) proposed the Computer-Supported Intentional Learning Environment (CSILE) to improve peer collaboration. Obikwelu, Read, and Sim (2013) explored children's problem solving in the Fun-Turing System. Howard, Jordan, Di Eugenio, and Katz (2015) designed the collaborative problem-solving dialogue agent to encourage peer dialogue and problem solving. These systems emphasized the sophisticated techniques to analyze the communication, control peer interaction, and manage the discussion process, but they lacked the design of organization structure of student group. The organizational relationship in these systems was usually loose.

One of the main reasons for the above problems is that these systems stress technology and neglect the research of problem solving itself, especially the learning mechanism related to problem solving. Aiming at these problems, this paper is organized as follows: firstly, we analyze the learning mechanism of problem solving, and propose that when designing Web-based problem solving systems, more attention should be paid to the learning mechanism involved in the problem solving process than to technology itself. Secondly, on the basis of that, some new ideas on the design of problem solving systems are presented. Question chain, a series of systematic and interlinked questions which are designed to guide students to find solution to problems, is proposed. Moreover, the theory of learning community is introduced to redesign the internal organization structure in Web-based learning systems. A new four-grade organization structure model is proposed from the perspective of the learning community to improve the students' problem solving performance. Finally, we conclude the article with a summary of our contributions.

\section{The Learning Mechanism of Problem Solving}

From the standpoint of learning, the essence of learning does not change at all compared with traditional learning in class, although learning online has changed greatly in the ways of acquiring knowledge. Thus when we design problem solving systems, the learning mechanism should be taken into consideration. 
The learning mechanism refers to students' active cognitive process of information processing (e.g., induction, deduction etc.; Kyprianidou, Demetriadis, Tsiatsos, \& Pombortsis, 2012). Therefore, the learning mechanism of problem solving refers to students' cognitive process of information processing during problem solving. According to van Merriënboer and Kirschner (2013), there are four components that could affect students' learning for problem solving. They are learning tasks, procedural information, supportive information, and part-task practice. Based on van Merriënboer and Kirschner's (2013) four-component instructional design model, paying attention to the four components could trigger students' learning mechanism and promote their problem solving skills.

Among the four components, learning tasks is the most important one. Van Merriënboer (2013) asserted that learning tasks need to be well-designed for students, which means that learning tasks should be set at an appropriate level of difficulty for students, and students can receive instructional support when they encounter more difficult learning tasks. However, when students learned in the existing Web-based learning systems oriented to problem solving, it is discovered that they could not receive appropriate learning tasks.

A common belief is that the design of Web-based learning systems oriented to problem solving should follow the rule of classification method of problems. However, it completely ignores learning needs of students. In fact, some learning tasks designed by classification methods could confuse students. In the area of problem solving, problems are divided into two categories: well-structured problems and ill-structured problems (Reitman, 1965; Jonassen, 2000). Well-structured problems have a single solution, optimal solution paths, and structured goals (Sinnott, 1989; Voss, 2005). By contrast, ill-structured problems have multiple solutions, diverse solution paths, vague goals, and require students' personal opinions combined in solving problems (Voss \& Post, 1988; Jonassen, 1997; Lynch, Ashley, Pinkwart, \& Aleven, 2009). This classification method of problems has long been used for years. However, the classification of problems in psychology is not applicable to the practice of problem solving in the field of education. Jonassen (1997, 2012), a researcher of educational technology, had made in-depth research on the two categories of problems. He pointed out that they were neither independent nor opposing to each other. Instead, they were connected to form a whole problem system. This study provides an important theoretical foundation for problem solving study in education. It clarifies that problems in the real world are various and complicated which usually possess the characteristics of well-structured problems and ill-structured ones. Van Merriënboer (2013) also supported the view that although the distinction between the two kinds of problem is reasonable from a theoretical point of view, real-life problems are a blend of well-structured problems and ill-structured ones. Furthermore, Jonassen (2004) argued that regardless of the kinds of problems, the cognitive processing engaged in solving them could be similar and the differences in problem solving depended on the context in which the problem occurred. In the field of education, problem solving should be learner-centered instead of problem-centered. More attention should be paid to cognitive processing (i.e., learning mechanism) when designing problem solving systems.

When students encounter difficult learning tasks, they need instructional supports which concern students' cognitive processing. According to Vygotsky (1978), when a student is at the ZPD (zone of proximal development) for a particular task, providing the appropriate scaffolding will give the students some motivation to accomplish a given task. ZPD refers to the distance between the "actual developmental level as determined by independent problem solving and the level of potential 
development as determined through problem solving under adult guidance or in collaboration with more capable peers" (p. 86). Based on Vygotsky's theory, many scaffolding strategies have been designed to scaffold students' problem solving. For instance, modeling (Schoenfeld, 2008), prompting (Scardamalia \& Bereiter, 2003) and questioning (King, 1991; Souvignier \& Kronenberger, 2007). Until now, most scaffolding strategies have been combined in the Web-based learning systems oriented to problem solving. However, there are many limitations as mentioned above on the design of those scaffolding strategies, which hinder students' learning.

Based on the analysis and rethinking of the learning mechanism of problem solving, some new ideas on the design of the problem solving systems are presented. In the study, we focus on the design of two scaffolding tools: question asking and peer collaboration.

\section{The Systemic Design of Question Asking from the Perspective of}

\section{Question Chain}

Many researchers have pointed out that one way to improve students' problem solving performance is to provide students with cognitive strategies and tools to facilitate cognitive processing (Jonassen, 1999, 2004; Lajoie, 2000). As an important cognitive strategy for providing scaffolding for student problem solving, question asking is attracting more and more attention from researchers (Cheung \& Hew, 2004; Ge \& Land, 2003; Uribe, Klein, \& Sullivan, 2003). Browne and Keeley (2007) thought that question asking could promote critical thinking, which was essential for problem solving (Jonassen, 2008).

Question asking takes many different forms according to the subject of questioning, which includes teacher questioning, self questioning, and computer questioning. Teacher questioning refers to teacher asking questions. Many researchers (e.g., Turner, 1980; Chin, 2006) have pointed out that the teacher level of questioning was a basic technique for guiding students through the search or inquiry process. Graesser and Olde (2003) focused on self questioning and pointed out that compared to poor problem solvers, better problem solvers asked high quality questions which lead to problem solving. Computer questioning refers to a computer or online system asking questions, such as question prompts. Question prompts have been proved effective in helping students represent and solve problems in various domains (Scardamalia \& Bereiter, 2003).

Although researchers have carried out studies on different forms of question asking, little research has been carried out on question asking itself, especially the systematic design of question asking. In the existing problem solving systems, systems would query students with questions, but these questions were usually arbitrary and separate. Thus it is difficult to guide students effectively to find solutions to problems. How to design the sequence of questions to promote students' problem solving effectively? In this study, we focus on the systematic design of question asking in problem solving systems and propose question chain, which is composed of a series of systematic and interlinked questions. These questions are used to elicit students' previous experiences; challenge students to resolve inconsistent views; guide students to establish relationships between existing knowledge and a new concept by 
explaining, reflection, and self-reasoning; and help students construct a new knowledge structure which can be applied to different situations.

An example is used to illustrate how the design of question chain will be implemented. Compressive force and pressure are one of the difficult knowledge points in middle-school physics lessons. Students often feel confused when they encounter problems concerning compressive force with pressure. Aiming at scaffolding students' cognitive processing, the question chain is designed as follows (shown in Table 1).

Table 1

Example of a Question Chain

\begin{tabular}{|c|c|c|}
\hline No. & Nature of questions & Examples \\
\hline \multirow[t]{2}{*}{1} & $\begin{array}{l}\text { Elicit previous } \\
\text { experiences }\end{array}$ & $\begin{array}{l}\text { Is the effect of pressure stronger when compressive force is } \\
\text { stronger? }\end{array}$ \\
\hline & & $\circ$ Yes (Go to 2$) \quad \circ$ No (Go to 3$)$ \\
\hline \multirow[t]{3}{*}{2} & Challenge previous & Example: Crawler cranes \\
\hline & experiences & $\begin{array}{l}\text { Do you still think that the effect of pressure is stronger when } \\
\text { compressive force is stronger? }\end{array}$ \\
\hline & & $\circ$ Yes (Stay) $\quad \circ$ No (Go to 3 ) \\
\hline \multirow[t]{4}{*}{3} & Guide and & What are the factors of pressure effect? \\
\hline & explanation & $\circ$ Only compressive force (Go to 4 ) \\
\hline & & $\circ$ Only area (Stay) \\
\hline & & ○ Compressive force and area（Go to 5 ） \\
\hline \multirow[t]{3}{*}{4} & Promote reflection & Example: What do you feel when a needle stabs the skin? \\
\hline & & $\begin{array}{l}\text { Can it explain that compressive force is the only factor of } \\
\text { pressure effect? }\end{array}$ \\
\hline & & $\circ$ Yes (Stay) $\quad \circ$ No (Go to 3 ) \\
\hline \multirow[t]{10}{*}{5} & Self reasoning & Example: The experiment of pressing sponge. \\
\hline & & Students can freely set the compressive force and load bearing \\
\hline & & surface area in order to observe different pressure effects. \\
\hline & & What is the relationship between the compressive force, area and \\
\hline & & pressure effect? \\
\hline & & $\circ$ For the same force, the pressure effect is stronger when surface \\
\hline & & area is bigger; (Stay) \\
\hline & & $\circ$ For the same force, the pressure effect is stronger when surface \\
\hline & & area is smaller; (Go to 6) \\
\hline & & $\begin{array}{l}\text { - For the same surface area, the pressure effect is stronger when } \\
\text { compressive force is bigger; (Go to } 6 \text { ) }\end{array}$ \\
\hline
\end{tabular}


○ For the same surface area, the pressure effect is stronger when compressive force is smaller; (Stay)

construction

How can we define the effect of pressure?

Force/area (Explain the concept of pressure and its formula)

Note: Stay means rethinking and trying to make a final decision.



Figure 1. The design of a question chain.

These six kinds of questions are interconnected and form a big chain (see black line in Figure1). Students follow this chain starting from question one and ending to question six, and are required to respond to each question put forward by the Web-based learning system. Once students finish a circle, they can review and manage their previous responses to questions, and they can also compare their solutions with those provided by the system.

\section{The Design of Internal Organization Structure from the Perspective of the Learning Community}

Peer collaboration is another promising strategy for providing scaffolding for students' problem solving (Johnson, 1988; Mergendoller et al., 2000; Adler, Zion \& Mevarech, 2015). According to Ge and Land (2003), peer collaboration has two types: guided interaction and unguided interaction. Traditionally, guided collaboration refers to students' collaborative activities guided by a teacher (e.g. Palincsar \& Brown, 1984). However, King's (1994) research showed that students could play the role of a teacher, and guide peer collaboration. Apart from guided peer interaction, unguided collaboration refers to students activated by group members to cooperate with each other. There are no given 
specified roles in the group (Webb, 1989; Capuano, Mangione, Mazzoni, Miranda, \& Orciuoli, 2014). It is the different abilities and skills possessed by students which help them learn from each other, and consider multiple points of views and possible solutions to problems. The analysis above illustrates that both guided peer interaction and unguided ones are important for students' problem solving.

Since students could not be actively enrolled in peer collaboration (Damon \& Phelps, 1989), it is necessary to focus on the design of scaffolding strategies to improve students' motivations to taking part in peer collaboration. Even though there is an agreement on incorporating peer collaboration into the development of problem solving systems (Tausczik, Kittur, \& Kraut, 2014), little effort has been paid to explore how to design scaffolding strategies to improve students' motivation to take part in peer collaboration online, for example, how to design different roles in peer collaboration, how to design the internal organization structure of the student group and so on are yet to be explored.

In this study, we introduce the theory of learning community to design the proper scaffolding framework for peer collaboration.

Smith, MacGregor, Matthews, and Gabelnick (2004) put forward that learning community was a variety of curricular approaches that intentionally link or cluster two or more courses, often around an interdisciplinary theme or problem, and enroll a common cohort of students. In other words, the learning community can be regarded as a variety of curricular approaches which are problem solving orientated. Smith and MacGregor (2009) believed that the learning community offered a very effective context for all students to pursue deep, lasting, personally significant, and integrated learning. Since learning community contains the connotation of problem solving and it can promote students' learning outcomes and their satisfaction towards learning in traditional class, it is reasonable to introduce learning community into the design of Web-based learning systems for problem solving, and improve students' online collaboration.

Wenger (1998) proposed that community was composed of three key elements: mutual engagement, joint enterprise, and shared repertoire. We introduce the three key elements into the learning organization of Web-based learning system oriented to problem solving. The three elements will be converted into the relationship between teachers and learners, the relationship between identification and consultation, and the interaction of explicit and implicit knowledge.

Based on the theory of learning community, a new four-grade organization structure model is proposed to promote the effective communication between teacher and students, which is shown in Figure 2. Different from existing Web-based learning systems in which usually there are only two roles (i.e., student and teacher), two new roles are added in the new organization structure model (i.e., learning guider and learning assistant).

As shown in Figure 2, there are four grades in the new organization structure model. The first and lowest grade is students represented as $S$. Students can form different groups. The second one is learning assistants represented as $A$. A learning assistant is the student selected randomly by the system in a group, who helps coordinate the cooperation among group members. The third one is learning guiders represented as $G$, who guides individuals or groups to focus on problem solving process, but they do not participate in problem solving. Learning guiders also record the group progress and report to the teacher. The fourth and highest one is the teacher represented as $T$, who 
provide help and guidance to activities of all levels and monitor the whole operation of the learning community.

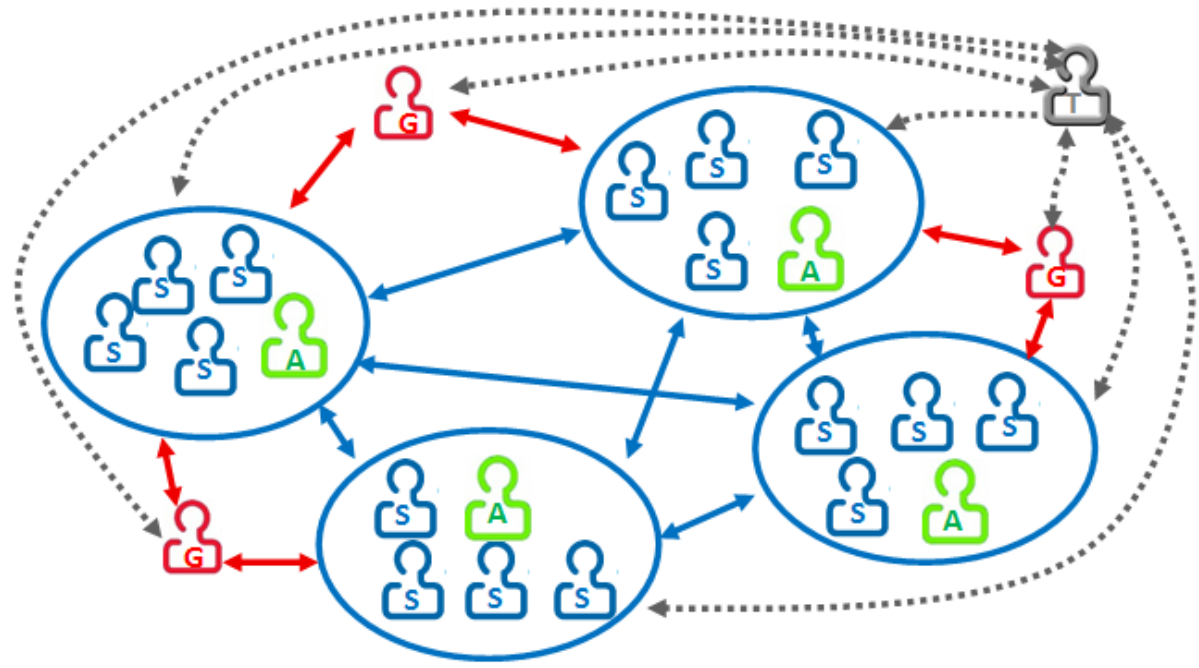

Figure 2. A new four-grade organization structure model of learning community.

Notes: "S" means students, "A" means learning assistants, "G" means learning guiders, and "T" means teachers

\section{Conclusion and Future Work}

The Web-based learning systems oriented to problem solving are attracting more and more attention for two main reasons. One lies in constantly renewed technology as more advanced technology is being applied to learning systems. The other is from the growing concern for learning itself. These two factors interpenetrate and interact with each other.

We propose that no matter what forms the Web-based problem solving systems take, the essence of learning does not change. The problem solving systems should be designed according to the learning mechanism. Some new ideas on the design of the problem solving systems are put forward. In the study, question chain is proposed and corresponding solving strategies are put forward. Meanwhile, the theory of learning community is introduced to design the internal organization structure in Web-based learning system. A new four-grade organization structure model is proposed in order to improve students' peer collaboration. These research results provide a new thinking way for the theory and practice of problem solving. Our future work is to design corresponding functions for the problem solving systems based on these new ideas in order to verify their applicability.

\section{Acknowledgements}

This paper is funded by the Youth Fund for Research on Humanity and Social Science by the Ministry of Education of the People's Republic of China (Project No. 14YJC880114) and by the Youth Fund for 
Research on Humanity and Social Science by Ocean University of China (Project No. 201564060).

\section{References}

Adler, I., Zion, M., \& Mevarech, Z. R. (2015). The effect of explicit environmentally oriented metacognitive guidance and peer collaboration on students' expressions of environmental literacy. Journal of Research in Science Teaching, 53(4), 620-663. doi:10.1002/tea.21272

Browne, M. N., \& Keeley, S. M. (2007). Asking the right questions: A guide to critical thinking (8 $8^{\text {th }}$ ed.). Upper Saddle River, NJ: Pearson Prentice Hall.

Capuano, N., Mangione, G. R., Mazzoni, E., Miranda, S., \& Orciuoli, F. (2014). Wiring role taking in collaborative learning environments. SNA and semantic web can improve CSCL script? International Journal of Emerging Technologies in Learning (iJET), 9(7), 30-38. doi:10.3991/ijet.v9i7.3719

Chang, K. E., Wu, L. J., Weng, S. E., \& Sung, Y. T. (2012). Embedding game-based problem-solving phase into problem-posing system for mathematics learning. Computers \& Education, 58(2), $775-786$.

Chen, C. H., \& Ge, X. (2006). The design of a web - based cognitive modeling system to support ill structured problem solving. British Journal of Educational Technology, 37(2), 299-302. doi: : 10.1111/j.1467-8535.2005.00480.x

Cheung, W. S., \& Hew, K. F. (2004). Evaluating the extent of ill-structured problem solving process among pre-service teachers in an asynchronous online discussion and reflection log learning environment. Journal of Educational Computing Research, 30(3), 197-227.

Chin, C. (2006). Classroom interaction in science: Teacher questioning and feedback to students' responses. International journal of science education, 28(11), 1315-1346.

Damon, W., \& Phelps, E. (1989). Critical distinctions among three approaches to peer education. International Journal of Educational Research, 13(1), 9-19.

Ge, X., \& Land, S. M. (2003). Scaffolding students' problem-solving processes in an ill-structured task using question prompts and peer interactions. Educational Technology Research and Development, 51(1), 21-38.

Graesser, A. C., \& Olde, B. A. (2003). How does one know whether a person understands a device? The quality of the questions the person asks when the device breaks down. Journal of Educational Psychology, 95(3), 524-536.

Howard, C., Jordan, P., Di Eugenio, B., \& Katz, S. (2015). Shifting the load: A peer dialogue agent that encourages its human collaborator to contribute more to problem solving. International Journal of Artificial Intelligence in Education, 1-29. 
Johnson, E. J. (1988). Expertise and decision under uncertainty: Performance and process. In M. T. H. Chi, R. Glaser \& M. J. Farr (Eds.), The nature of expertise (pp. 209-228). Hillsdale, NJ: Erlbaum.

Jonassen, D. H. (1997). Instructional design model for well-structured and ill-structured problem-solving learning outcomes. Educational Technology Research and Development 45(1), 65-95.

Jonassen, D. H. (1999). Designing constructivist learning environments. In C.M. Reigeluth (Ed.), Instructional-design theories and models (2nd ed., pp. 215-240). Mahwah, NJ: Lawrence Erlbaum Associates.

Jonassen, D. H. (2000). Toward a design theory of problem solving. Educational Technology Research and Development, 48(4), 63-85.

Jonassen, D. H. (2004). Learning to solve problems: An instructional design guide. San Francisco, CA: Pfeiffer/Jossey-Bass.

Jonassen, D. H. (Ed.) (2007). Learning to solve complex scientific problems. New York, NY: Lawrence Erlbaum.

Jonassen, D. H. (2008). Meaningful learning with technology. Pearson/Merrill Prentice Hall.

Jonassen, D. H. (2012). Designing for decision making. Educational Technology Research and Development, 6o(2), 341-359.

King, A. (1991). Effects of training in strategic questioning on children's problem-solving performance. Journal of Educational Psychology, 83(3), 307-317.

King, A. (1994). Guiding knowledge construction in the classroom: Effects of teaching children how to question and how to explain. American Educational Research Journal, 31(2), 338-368.

Kyprianidou, M., Demetriadis, S., Tsiatsos, T., \& Pombortsis, A. (2012). Group formation based on learning styles: Can it improve students' teamwork? Educational Technology Research and Development, 6o(1), 83-110.

Lajoie, S. (2000). Computers as cognitive tools: No more walls: Theory change, paradigm shifts and their influence on the use of computers for instructional purposes. Mahwah, NJ: Lawrence Erlbaum Associates.

Li, H., Duan, Y., Clewley, D. N., Morgan, B., Graesser, A. C., Shaffer, D. W., \& Saucerman, J. (2014, January). Question asking during collaborative problem solving in an online game environment. In Intelligent tutoring systems (pp. 617-618). Switzerland: Springer International Publishing. doi:10.1007/978-3-319-07221-0 80

Lin, G. Y. (2011). Designing a web-based collaborative-learning module for statistical problem solving. British Journal of Educational Technology, 42(3), E54-E57.

Lovett, M. C. (2002). Problem solving. In D. Medin (Ed.), Stevens' handbook of experimental 
psychology: Memory and cognitive processes ( $3^{\text {rd }}$ ed.; pp. 317-62). New York, NY: Wiley. doi: 10.1002/0471214426. pas0208

Lynch, C., Ashley, K. D., Pinkwart, N., \& Aleven, V. (2009). Concepts, structures, and goals: Redefining ill-definedness. International Journal of Artificial Intelligence in Education, 19(3), 253-266.

Mergendoller, J. R., Bellisimo, Y., \& Maxwell, N. L. (2000). Comparing problem-based learning and traditional instruction in high school economics. Journal of Educational Research, 93(6), $374-383$.

Obikwelu, C., Read, J., \& Sim, G. (2013). Children's problem-solving in serious games: The "Fine-Tuning System (FTS)" Elaborated. Electronic Journal of e-Learning, 11(1), 49-60.

Palincsar, A. S., \& Brown, A. L. (1984). Reciprocal teaching of comprehension-fostering and comprehension-monitoring activities. Cognition and Instruction, 2, 117-175.

Popper, K. (1999). All life is problem solving. London: Routledge.

Popper, K. (2013). Knowledge and the body-mind problem: In defence of interaction. London: Routledge.

Reitman, W. R. (1965). Cognition and thought. New York, NY: Wiley.

Scardamalia, M., \& Bereiter, C. (2003). Knowledge building environments: Extending the limits of the possible in education and knowledge work. In A. DiStefano, K. E. Rudestam, \& R. Silverman (Eds.), Encyclopedia of distributed learning (pp. 269-272). Thousand Oaks, CA: Sage.

Scardamalia, M., \& Bereiter, C. C. \& Lamon, M.(1994) The CSILE Project: Trying to bring the classroom into World 3. Classroom Lessons: Integrating Cognitive Theory and Classroom Practice, 201-228.

Schoenfeld, A. H. (2008). A study of teaching: Multiple lenses, multiple views. Journal for Research in Mathematics Education, Monograph 14. Reston, VA: National Council of Teachers of English.

Sinnott, J. D. (1989). A model for solution of ill-structured problems: Implications for everyday and abstract problem solving. In J.D. Sinott (Ed.), Everyday problem solving: Theory and application (pp. 72-99). New York, NY: Praeger.

Smith, B.L., J. MacGregor, R.S. Matthews \& F. Gabelnick (2004). Learning communities: Reforming undergraduate education. San Francisco: JosseyBass.

Smith, B. L., \& MacGregor, J. (2009). Learning communities and the quest for quality. Quality Assurance in Education, 17(2), 118-139. doi:10.1108/09684880910951354

Souvignier, E., \& Kronenberger, J. (2007). Cooperative learning in third graders' jigsaw groups for mathematics and science with and without questioning training. British Journal of Educational Psychology, 77(4), 755-771. 
Spiro, R. J., Coulson, R. L., Feltovich, P. J., \& Anderson, D. K. (1988). Cognitive flexibility theory: Advanced knowledge acquisition in ill-structured domains. Cognitive Science, 12, 257-285.

Spiro, R. J., Morsink, P., \& Forsyth, B. (2012). Point of view: Principled pluralism, cognitive flexibility, and new contexts for reading. In R. F. Flippo (Ed.) Reading researchers in search of common ground: The expert study revisited (pp. 118-128). New York: Routledge.

Tausczik, Y. R., Kittur, A., \& Kraut, R. E. (2014, February). Collaborative problem solving: A study of mathoverflow. In Proceedings of the 17th ACM conference on Computer supported cooperative work \& social computing (pp. 355-367). New York: ACM.

The Adventures of Jasper Woodbury. (n.d.). Retrieved from http://jasper.vueinnovations.com/adventures-of-jasper-woodbury

Turner, P. H. (1980). Teacher level of questioning and problem solving in young children. Home Economics Research Journal, 8(6), 399-404.

Underdahl, J., Palacio-Cayetano, J., \& Stevens, R. (2001). Practice makes perfect: Assessing and enhancing knowledge and problem solving skills with IMMEX software. Learning and Leading with Technology, 28(7), 26-31.

Uribe, D., Klein, J. D., \& Sullivan, H. (2003). The effect of computer-mediated collaborative learning on solving ill-defined problems. Educational Technology Research \& Development, 51(1), 5-19.

van Merriënboer, J. J. G. (2013). Perspectives on problem solving and instruction. Computers \& Education, 64, 153-160.

van Merriënboer, J. J. G., \& Kirschner, P. A. (2013). Ten steps to complex learning: A systematic approach to four-component instructional design (2nd ed.). New York, NY: Routledge.

Voss, J. F. (2005). Toulmin's model and the solving of ill-structured problems. Argumentation, 19(3), $321-329$.

Voss, J. F., \& Post, T. A. (1988). On the solving of ill-structured problems. In M. H. Chi, R. Glaser, \& M. J. Farr (Eds.), The nature of expertise (pp. 261-285). Hillsdale, NJ: Lawrence Erlbaum.

Vygotsky, L. S. (1978). Mind and society. Cambridge, MA: Harvard University Press.

Webb, N. M. (1989). Peer interaction and learning in small groups. International Journal of Educational Research, 13, 21-39.

Wenger, E. (1998), Community of practice: Learning, meaning, and identity. Cambridge: Cambridge University Press.

Wu, B., Wang, M., Spector, J. M., \& Yang, S. J. (2013). Design of a dual-mapping learning approach for problem solving and knowledge construction in ill-structured domains. Journal of Educational Technology \& Society, 16(4), 71-84. 


\section{Athabasca}

University

(c) (†) 